\title{
A Survey of Different Machine Learning Models for Alzheimer Disease Prediction
}

\author{
Ragavamsi Davuluri ${ }^{1}$, Ragupathy Rengaswamy ${ }^{2}$ \\ ${ }^{1}$ Department of Computer Science and Engineering, Annamalai University, Annamalainagar, \\ Tamil Nadu - 608002, India, raaga.vamsi@gmail.com \\ ${ }^{2}$ Department of Computer Science and Engineering, Annamalai University, Annamalainagar, \\ Tamil Nadu - 608002, India, cse_ragu@ yahoo.com
}

\begin{abstract}
Machine learning model is one of the best disease prediction framework in various medical disease prediction processes. Alzheimer's disease (AD) is a progressive neuro-degenerative condition with different severity features. However, it is noted that very few patients who is suffering from Alzheimer's disease are decided to take correct clinical decision making. Most of the traditional machine learning models help to detect the AD with limited feature space and dimensionality. Also, these models are not applicable to high dimensional features due to sparsity problem. Several high dimensional classification and clustering methods have recently been proposed to predict the $\mathrm{AD}$ automatically. Component selection plays a significant role in improving the performance of these programs. Therefore, various forms of feature selection techniques are analyzed in this survey article. The purpose of the paper is to include an analytical overview and strategic examination of the latest research work performed using Machine Learning Strategies to early diagnosis of $\mathrm{AD}$.
\end{abstract}

Key words : Alzheimer's disease, Feature Selection, supervised models and unsupervised models.

\section{INTRODUCTION}

Alzheimer's disease (AD), a widespread health problem which causes memory loss and kills nerve cells in the elderly, constitutes a degenerative brain condition. AD has different stage like the early stage, moderate phase, severe phase (late phase). In order to be able to make preemptive action, it is necessary to detect AD early in the MCI. The world's fourth most common cause of death reported in 2009 is AD, the most prevalent form of dementia. Diagnose of AD calls for several methods of neuroimaging and neuropsychological clinical data. The main clinical characteristics of mild cognitive impairment (MCI) are memory complaint, normal cognitive function, and abnormal age memory. The memory loss in the MCI participants is similar but less disabled than moderate $A D$ patients in other areas. Over time, MCI individuals reported lower decreases than patients with moderate $\mathrm{AD}$. MCI memory deficits may remain stable for years in comparison to $\mathrm{AD}$, where there is slow decline in cognitive ability. Many people with MCI, however, experience AD-compatible cognitive and functional disabilities. The most common prodromal phase of $\mathrm{AD}$ was $\mathrm{MCI}$, and current studies have shown MCI people continue to progress towards $\mathrm{AD}$ at around $10-15 \%$ annually [3].Annual conversion rate of $\mathrm{MCI}$ into $\mathrm{AD}$ could be up to $25 \%$ [2], according to the American Academy of Neurologies, which reviewed a number of trials in 2001.

Alzheimer's disease is hard to be scientifically diagnosed, and signs are often ignored as natural effects of aging. Diagnosis is usually done by a combination of extensive testing and other potential causes. For example, if the patient has suffered from a serious head injury at any time in his or her past or heart problems, they may have problems with memory or concentration. The test should include an anxiety or depression assessment that can lead to symptoms similar to Alzheimer's in seniors, as well as to Alzheimer's or other dementia concurrently. In fact, depression can lead to a generalized set of symptoms known as pseudodementia. In order to assess a patient's memory, concentration and other cognitive skills, a mental status test such as Mini Mental State Examinations is being done, a research based set of issues leading to a score that shows the general degree of impairment. Typically, if the score is very small, $A D$ is less probable. Nevertheless, highly trained people have high mental status checks, although they have Alzheimer's disease. The role of Neuropsychological (NP) evaluations has advanced to that of evaluating the Cognitive and psychosocial consequences of brain damage that is often well located. NP may be very useful for early diagnosis and differentiation between Normal Control, MCI and AD and also to determine if a patient is responding to treatment. Reliable and standardized neuropsychological batteries are used. They are easier to administer, cheaper than neuroimaging, less time consuming, and early accuracy picks up brain damage. Dementia diagnosis from Alzheimer needs data from multiple modalities of neuroimaging and clinical data obtained through neuropsychological testing. Although the studies had used various criteria for MCI. The heterogeneous nature of MCI 
subjects has defined these MCI subjects correctly as they are a target group for early therapeutic interventions with the strongest biomarkers in AD [6]. Using imaging biomarks, different $\mathrm{AD}$ patterns are used to find the disorder, either in cognitively disabled or in unimpaired adults, by recognizing pathology and neuro degeneration [8].

Diagnosis of $\mathrm{AD}$ can be performed through multiple algorithms [1], [3]. For the analysis and classification of AD data, many fully automated and semi-automatic methods have been used. Ongoing research focuses on AD for determining biomarkers that will better predict future cognitive decline, particularly in early phases of the progression of disease. In clinical medicine, the development of automated detection procedures based on MRI and other imaging technology is of great interest. It is important to note that these approaches are intended to help clinicians with additional statistical evidence for diagnosis, and that these biomarkers are eventually hoped to act as early markers for AD diagnosis [7]. For early intervention and to control progression of diseases, early diagnosis is very important. The subsequent diagnosis and treatment prove harmful and increases the rate of disease and mortality. As, data volume increases, the specificity and susceptibility of current methods will decrease. It was difficult to diagnose Alzheimer's disease exactly due to dementia [37], [47]. AD is the utmost common form of brain disorder caused due to regular loss of cognitive function such as episodic memory [41]. AD diagnosis specifies a severe cognitive impairment and autopsy evidence of histopathological brain changes.

This paper is systematized as follows. A short description of machine learning models of Alzheimer's disease prediction is presented in section 2. Many feature selection approaches and related work on component selection methods is compared in section 3 . In section 4 , a survey on traditional supervised learning systems for $\mathrm{AD}$ prediction and in section 5, a survey on traditional unsupervised learning systems for Alzheimer's disease prediction is presented. Finally, conclusion is made in section 6.

\section{ALZHEIMER'S DISEASE PREDICTION}

The identification of AD plays a essential role in the continuum of health care. At an early stage, it is essential to diagnose the disease. For prevision of disease severity [4], [5] $\mathrm{AD}$ diagnosis may either be identified using supervised or uncontrolled learning methods. There are a number of different classification algorithms available. For the prediction of AD disease, supervised models such as support vector machine (SVM), random Forest (RF) and decision tree (DT) are used. The data is usually separated into training and test sets. The classifier is from training set designed and tested by means of a separate test set. The data is divided in $\mathrm{N}$ parts with a distribution of almost the same size and class. The classifier is composed of N-1 subsets and the rest of the subsets are used for testing. Cross-validation for random partitions can be repeated several times. The average measures calculated from various cross validation times are fairly reliable estimates of the performance of a classifier based on the entire training data. Figure 1 demonstrates how the processed data are used to obtain the predictive results by the controlled learning procedure. The prediction of $\mathrm{AD}$ is made by unregulated models such as k-means, hierarchical clusters and Density-based spatial clusters of applications with noise (DBSCAN). Figure 2 shows how data are used to achieve the predictive results in the unsupervised learning process. 


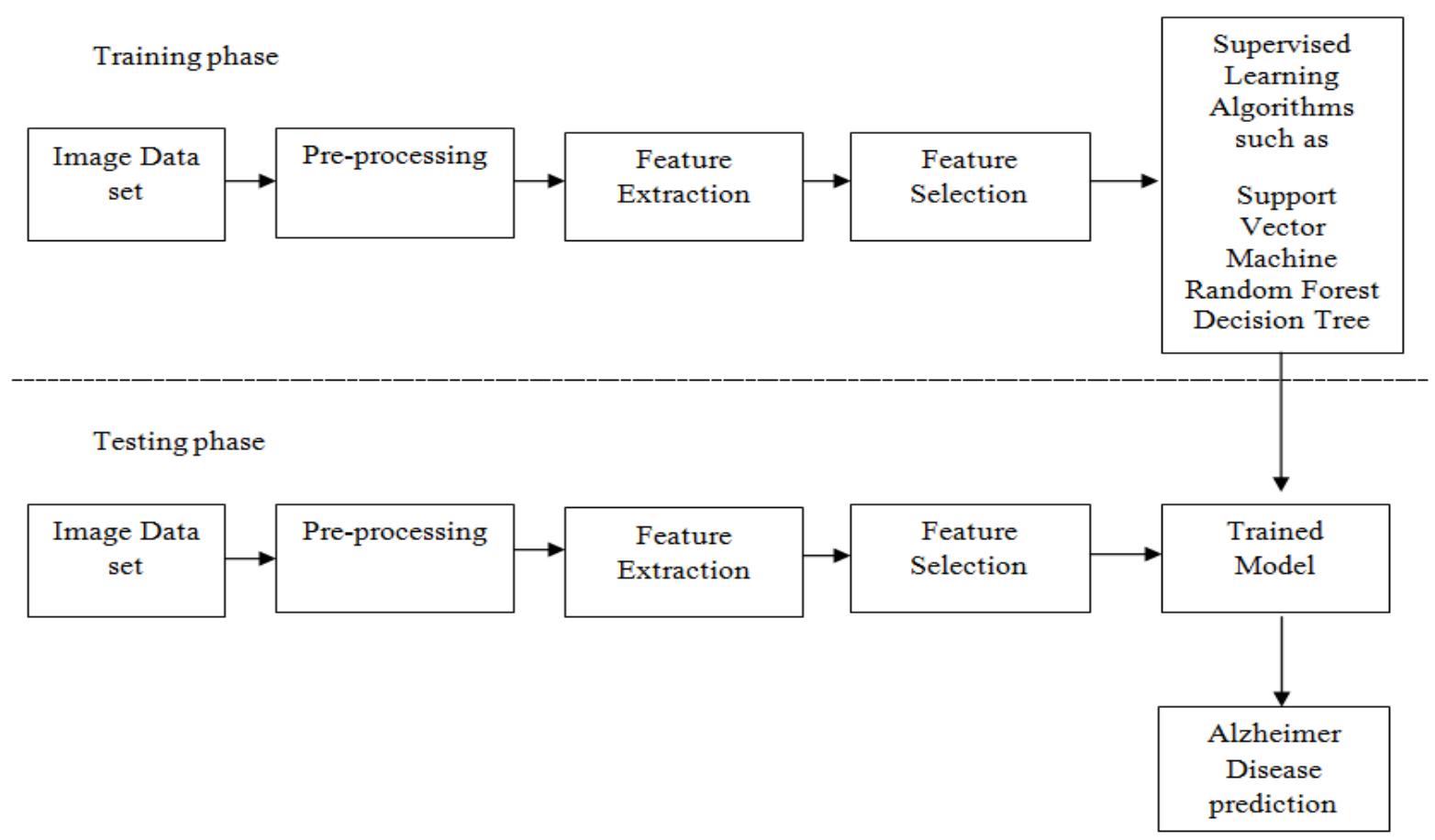

Figure 1: Supervised learning process

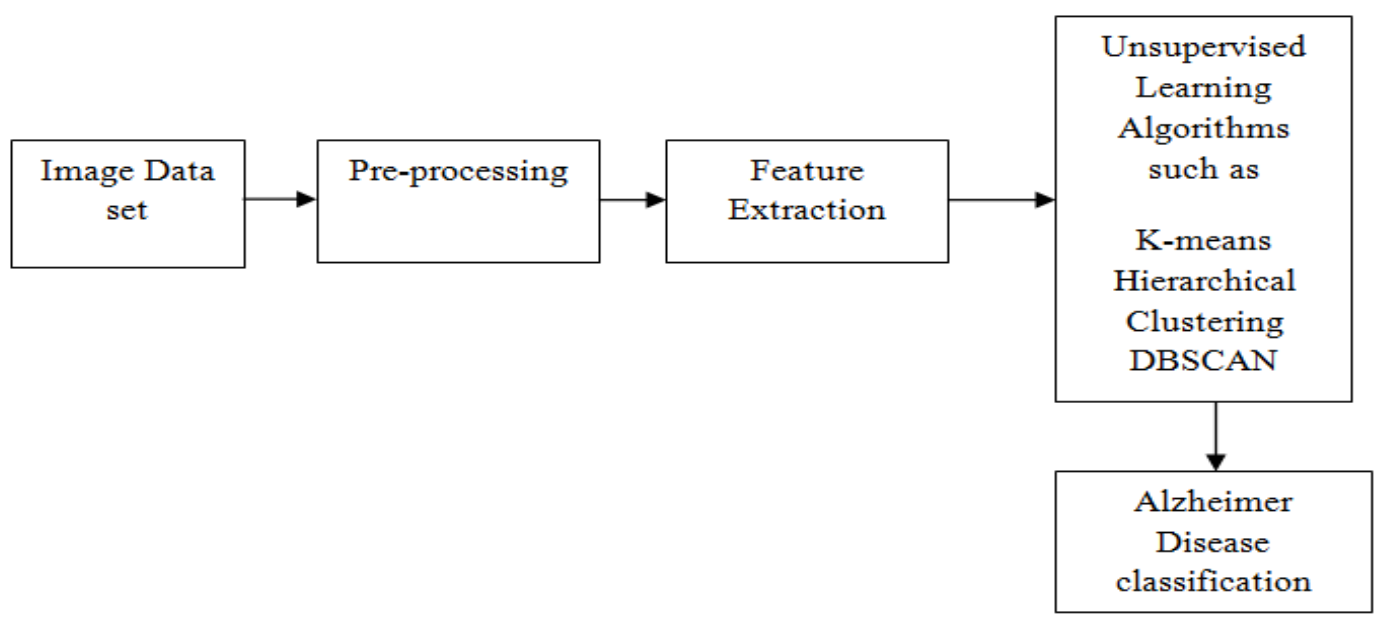

Figure 2: Unsupervised learning process

\section{TRADITIONAL FEATURE SELECTION MODELS}

Feature selection is one of the significant steps in data mining and machine learning. Feature selection techniques in domains where many features exist are often used. It is a time-consuming job to use all the features for classification of diseases. Moreover, a few features may help Alzheimer's disease more while the rest may contribute little. In medical diagnoses, the most important risk factors related to Alzheimer's disease are very important to identify. Relevant feature identification helps to remove superfluous, redundant attributes from the images data set, reducing training time and improving prediction performance [30].
In recent years different approaches to identifying features in health data sets have been used to provide more valuable information. Few methodologies for selecting the optimal feature set were studied [29]. This protocol proposes a multi-tasking hypergraph approach to select $\mathrm{AD} / \mathrm{MCI}$ classification, which is used as one function for each modality and integrates group-sparsity regularizer in order to pick similar features together across multiple modalities. This approach is built on the selection of each model. In order to model high-order structural relations between subjects shao et al. [24] introduced the hyper graph based regulation term for a standard selection of the multi-tasking function. Lastly, a multi-kernel SVM is used in order to combine the selected features of various classification modalities. Anatomical parceling by registration 
with an atlas to group voxels of the different anatomical regions was one approach used in this study [3]. In multi-class scenarios, it is important to delineate the narrow boundary between several classes, which is explored by specific sampling techniques and feature selection techniques in current Alzheimer's Dementia studies [9]. Ramesh et al. [35] compares diagnostic approaches to structural magnetic resonance imaging using the SVM, the import vector machine, and the regularized extreme learning machine to discriminate against $\mathrm{AD}, \mathrm{MCI}$ and healthy-constrained subjects (HC-subjects). The greedy score based technique for the selection of important functional vectors is used.

Several research works [10], [11] have tried to classify multimodal with machine learning classifiers primarily for binary classification of neuroimaging modalities such as MRI. Table 1 depicts few more component selection techniques developed in recent years and their findings.

Table 1: Feature selection models

\begin{tabular}{|c|c|c|c|c|c|}
\hline Author & Year & Model & $\begin{array}{c}\text { Feature selection } \\
\text { technique(s) }\end{array}$ & Metrics & Findings \\
\hline $\begin{array}{c}\text { Wang } \\
\text { et al. [44] }\end{array}$ & 2019 & $\begin{array}{l}\text { Subspace-based } \\
\text { sparse feature } \\
\text { learning method }\end{array}$ & $\begin{array}{c}\text { Principal } \\
\text { component } \\
\text { analysis (PCA) } \\
\text { and linear } \\
\text { discriminant } \\
\text { analysis (LDA) }\end{array}$ & Accuracy :0.856 & $\begin{array}{l}\text { Experimental findings } \\
\text { indicate that the } \\
\text { functional parameters } \\
\text { extracted are better on } \\
\text { small set of } \\
\text { AD features. }\end{array}$ \\
\hline $\begin{array}{l}\text { Trambaiolli } \\
\text { et al. [55] }\end{array}$ & 2017 & $\begin{array}{c}\text { Filtered subset } \\
\text { evaluation } \\
\text { Technique }\end{array}$ & $\begin{array}{c}\text { Consistency-Based } \\
\text { Filter(CBF) } \\
\text { Filtered Subset } \\
\text { Evaluator (FSE) } \\
\text { Chi Squared (CS) } \\
\text { Gain Ratio (GR) } \\
\text { Correlation-Based } \\
\text { Feature Selection } \\
\text { (CFS) } \\
\text { Relief-F } \\
\text { Symmetrical } \\
\text { Uncertainty (SU) } \\
\text { Ensemble Feature } \\
\text { Selection (EFS). }\end{array}$ & Accuracy:0.913 & $\begin{array}{l}\text { Electroencephalography } \\
\text { (EEG) datasets attain } \\
\text { better precisions with } \\
\text { pre-processing FS steps. }\end{array}$ \\
\hline $\begin{array}{l}\text { Tejeswinee } \\
\text { et al. [29] }\end{array}$ & 2017 & $\begin{array}{l}\text { Decremental } \\
\text { Method }\end{array}$ & $\begin{array}{c}\text { Correlation } \\
\text { Feature Subset } \\
\text { Selection (CFS), } \\
\text { Information Gain } \\
\text { (IG) and Gain } \\
\text { Ratio (GR) }\end{array}$ & Accuracy:0.937 & $\begin{array}{l}\text { A new dataset consisting } \\
\text { of genetic data relating } \\
\text { to the neurodegenerative } \\
\text { condition was created. }\end{array}$ \\
\hline $\begin{array}{l}\text { Mirzaei } \\
\text { et al. [51] }\end{array}$ & 2018 & $\begin{array}{c}\text { Two-Stage } \\
\text { Feature } \\
\text { Selection of } \\
\text { Voice metrics. }\end{array}$ & $\begin{array}{l}\text { Wrapper based } \\
\text { feature selection } \\
\text { model }\end{array}$ & Accuracy :0.78 & $\begin{array}{l}\text { The selection scheme } \\
\text { removes specific } \\
\text { characteristics from the } \\
\text { speech in pathology } \\
\text { classes. }\end{array}$ \\
\hline $\begin{array}{c}\text { Jiaye } \\
\text { et al. }[50]\end{array}$ & 2019 & $\begin{array}{c}\text { Feature } \\
\text { Selection based } \\
\text { multi-view } \\
\text { learning }\end{array}$ & $\begin{array}{c}\text { A } \\
\text { multi-view sparse } \\
\text { exclusive lasso } \\
\text { feature selection } \\
\text { algorithm } \\
\end{array}$ & Accuracy :0.897 & $\begin{array}{c}\text { Achieved strong } \\
\text { diagnostic and } \\
\text { robustness performance } \\
\text { for small datasets. }\end{array}$ \\
\hline $\begin{array}{c}\text { Xiaoke } \\
\text { et al. [49] }\end{array}$ & 2019 & $\begin{array}{c}\text { Multi-modal } \\
\text { neuroimaging } \\
\text { Feature } \\
\text { Selection } \\
\text { with Consistent } \\
\text { Metric } \\
\text { Constraint } \\
\end{array}$ & $\begin{array}{l}\text { Multi-modal } \\
\text { neuroimaging } \\
\text { feature selection } \\
\text { method }\end{array}$ & Accuracy :0.93 & $\begin{array}{l}\text { This approach is utilized } \\
\text { to integrate additional } \\
\text { data for task selection } \\
\text { and further classification } \\
\text { from multi-modal } \\
\text { neuroimaging. }\end{array}$ \\
\hline
\end{tabular}


Ragavamsi Davuluri et al., International Journal of Emerging Trends in Engineering Research, 8(7), July 2020, 3328 - 3337

\section{TRADITIONAL SUPERVISED MACHINE LEARNING MODELS}

Supervised learning involves training the model for the labelled data and makes predictions on the new data using this trained model. The data is split into two sets of training and test system elements. The model is trained first in a training package and then testing performance on the test package. The efficiency of the model can be measured with output measurements. The main goal of supervised learning is to draw from the data a learning model which can predict unknown knowledge. These models can be used to identify Alzheimer's disease.

Current therapies cannot prevent the progression of Alzheimer, but can delay the deterioration of the symptoms. The medical history, laboratory tests, physical examinations and neuropsychological assessments are used for the clinical diagnosis of Alzheimer, as they measure the person's memory, attention, language skills and problem-solving ability. The diagnosis confirms whether the deficiencies are appropriate for an adult with ordinary daily functions. At 0.85 AUC, 15 MRIs, apolipoprotein $\mathrm{E}$ and cognitive testing properties are obtained at the highest level. These findings further show the effectiveness of selection of stability in the sense that the logistic regression of functional selection is scarce [33]. Hannah et al. [14] studied MRI data base, using logistic regression, SVM, radial basic function and $\mathrm{C} 4.5$ tree study methods, for $\mathrm{AD}, \mathrm{MCI}$ and Control Subject Classifications on Alzheimer disease neuroimaging initiative (ADNI). Classification and Regression Trees is an effective tool for the mining of high quality conversion predictors from a high-dimensional data set. In signalizing conversions, CART was useful to confirm the importance of functional action in the MCI population. CART is also a valuable method for identifying covariates for biomarker and neuroimaging that better predict the disease's progression [16]. 89.2 percent and 72.7 percent respectively were maximum precision rates for the $\mathrm{AD}$ and $\mathrm{MCI}$ control classifications [12]. The analysis of MRI 3D-brain images with an SVM and other well established classifiers to predict $\mathrm{AD}$ was projected by Matoug et al. [18]. The ADNI dataset is used for investigation. Throughout this analysis, the pseudo automated technique for reading volumetric rheumatism is introduced, the middle parts of the brain region are extracted, the ventricular region is segmented, a vector characterizing the area is created, a database of SQL containing the data produced and classifying pictures based on extracted features. RF and SVM classification methodologies were identified by Tripoliti et al. [15] for an exact classification of $\mathrm{AD}$. The MRI-based features are extracted and evaluated using an RF grading then interpreted using SVM. [22] Submitted an SVM-based Alzheimer's disease (AD) classification system that incorporates spatial and anatomical details. This encourages space neighbors to have similar weights on the SVM model in the same anatomic region. Secondly, we add a lasso group penalty that can help clinicians determine the key disease-involving regions in induce structural sparsity. The quantitative Voxel morphometric approach to the progression of $\mathrm{AD}$ in gray matter was introduced by Daniel et al. [23]. Plant et al. [17] identified using MRI and a combination of three classifiers including SVM, data on Bayes and voting interval strategies to discriminate $\mathrm{AD}$ patients from healthy controls, and also forecast the change from MCI to AD. In [26], model consists of four components: preprocessing, segmentation, extraction and classification of features. The extraction of texture characteristics from the observed tumor was accomplished with the use of Gray level co-occurrence matrix (GLCM). The extracted functions are fed to the SVM classifier as an input. Categorization of images from normal to abnormal according to characteristics was done [20]. A Simple drawing movements in Alzheimer's disease was emphasized in [19]. It is capable of differentiating healthy state from diseased state by simply drawing straight lines. There were certain other approaches which involve writing words, drawing spirals and circles. White matter hyper-intensities normally require expert to do manual segmentation/classification on Fluid-attenuated magnetic resonance ADNI. It is difficult to perform consistent and accurate segmentation of white matter hyper intensities for a couple of reasons. Their patterns and texture were heterogeneous, and the borders between the intensities are not clear. The main problem to determine the border between the non-white matter hyper intensities (WMH) and $\mathrm{WMH}$ tissue make it better to use the intra-range and inter-range agreements. Detection of WMHs uses various MRI contrasts such as fluid attenuated inversion recovery which shows the hyper-intensity of WMHs, proton density, T2-w, and T1-w which is mostly useful for co-registration [31]. Liu et al. [27] proposed a framework of multiple kernels for disease prediction process.

An ensemble of SVMs that combined bagging without replacement and selection of features. SVM is widely used procedure in detecting dementia. The ensemble approach was motivated by the RF algorithm. In particular, bagging with sequential forward feature selection in the SVM classification has achieved better performance in identifying Alzheimer's disease [32]. More supervised learning models were developed recently and were compared in table 2 . 
Ragavamsi Davuluri et al., International Journal of Emerging Trends in Engineering Research, 8(7), July 2020, 3328 - 3337

Table 2: Supervised learning models

\begin{tabular}{|c|c|c|c|c|c|}
\hline Author & Year & Model & $\begin{array}{l}\text { Feature } \\
\text { selection } \\
\text { technique } \\
\text { (s) }\end{array}$ & Metrics & Discovery \\
\hline $\begin{array}{c}\text { Vaithinathan } \\
\text { et al. [56] }\end{array}$ & 2019 & $\begin{array}{l}\text { Texture Extraction } \\
\text { Technique based } \\
\text { classification }\end{array}$ & $\begin{array}{l}\text { Fisher score, } \\
\text { elastic net and } \\
\text { recursive } \\
\text { feature } \\
\text { elimination. }\end{array}$ & Accuracy:0.87 & $\begin{array}{c}\text { Extracts the } \\
\text { characteristics from } \\
\text { other fields of } \\
\text { interest and analyzes } \\
\text { texture. }\end{array}$ \\
\hline $\begin{array}{l}\text { Pietro } \\
\text { et al. [45] }\end{array}$ & 2020 & $\begin{array}{l}\text { Electroencephalography } \\
\text { (EEG) and functional } \\
\text { Near-Infrared Spectroscopy } \\
\text { (fNIRS) hybrid Technique }\end{array}$ & $\begin{array}{c}\text { Pearson } \\
\text { correlation } \\
\text { coefficient-base } \\
\text { d feature } \\
\text { selection } \\
\text { (PCCFS) } \\
\text { strategy }\end{array}$ & Accuracy: 0.903 & $\begin{array}{l}\text { This model supports } \\
\text { (and evaluates) } \\
\text { dementia in AD } \\
\text { patients cheaply and } \\
\text { rapidly. }\end{array}$ \\
\hline $\begin{array}{c}\text { Atlaf } \\
\text { et al. [26] }\end{array}$ & 2018 & $\begin{array}{l}\text { SVM, K-nearest neighbor } \\
(\mathrm{KNN}), \text { Decision Tree and } \\
\text { Ensemble }\end{array}$ & GLCM & $\begin{array}{c}\text { Accuracy:0.98 } \\
\text { sensitivity:0.97, and } \\
\text { specificity: } 0.98\end{array}$ & $\begin{array}{l}\text { Visual features } \\
\text { extracted from } \\
\text { structural MRI using } \\
\text { GLCM, scale } \\
\text { invariant feature } \\
\text { transform, } \\
\text { histogram of } \\
\text { gradient and local } \\
\text { binary pattern } \\
\text { contribute much in } \\
\text { the prediction. }\end{array}$ \\
\hline $\begin{array}{l}\text { Kruthika } \\
\text { et al. [43] }\end{array}$ & 2019 & Multi-class classifier & $\begin{array}{l}\text { PSO (particle } \\
\text { swarm } \\
\text { optimization) }\end{array}$ & $\begin{array}{c}\text { Accuracy:0.96 } \\
\text { Sensitivity:0.91 } \\
\text { Specificity:0.89 } \\
\text { Precision:0.96 }\end{array}$ & $\begin{array}{l}\text { The technique of } \\
\text { function selection } \\
\text { was examined using } \\
\text { multiple MRI } \\
\text { scanning function } \\
\text { sets: cortical } \\
\text { thickness, volume } \\
\text { features, and a } \\
\text { thickness/ volume } \\
\text { combination. }\end{array}$ \\
\hline
\end{tabular}

\section{TRADITIONAL UNSUPERVISED MACHINE LEARNING MODELS}

Unsupervised Learning does not involve any training of the data. In this, machine tries to cluster the correlated type of the data by finding the hidden patterns rather than making predictions. These models could also be used for the prediction of $\mathrm{AD}$.

$\mathrm{AD}$ is a chronic neurodegenerative progressive and irreversible syndrome. In enhancing AD diagnostics Miguel et al. [21] uses electroencephalograms (EEG). K-means are used for this, and the findings show that sequences of EEG energy change occur in $\mathrm{AD}$ patients more commonly than in healthy subjects. Clear detection and recognition of morphological variations within the brain is critical for pre-surgical preparation for the treatment of AD. MRI can detect $\mathrm{AD}$ as well as frequency for patients. To achieve accurate volumes of various problems in the brain, the gray matter, white matter, cerebrospinal fluid and the hippocampus segmentation is required. The development and classification techniques for Alzheimer's, MCI and normal control subjects are clearly defined in this study. As a hybrid segmentation strategy [53], the $\mathrm{K}$-means and graph cutting technique is used. Paul et al. [39] used a clustering approach k-means, and they have linguistic and neuropsychological profile-based patients classified. The CDR score was based on the recruitment of CDR1 $(n=16)$, CDR2 ( $n=15)$, CDR3 ( $n=13)$ and grouped in three groups in [36] AD patients aged 60 or older. Healing volunteers were also recruited to the age group $(n=16)$. Images from a brain were attained on a $3 \mathrm{~T}$ magnetic resonance scanner using a conventional Gradient eco 3D T1-w sequence without contrast 
injection. Volumetric quantifiable data and cortical thickness were generated in automated segmentation. Moreover this method provides better understanding on the $\mathrm{AD}$ pathophysiologic process. Charles [40] has a model-based categorization of highly dimensional structural neuroimaging data that provides an open approach to personal study. Cortical thickness measurements for 369 older adults were acquired from the ADNI. Poulakis et al. [25] has identified heterogeneous atrophy patterns in the brain in Alzheimer's disease. Han et al. [28] also suggested that earlier Alzheimer's stages may be categorized into three anatomical subtypes: media temporal, parietal, and diffuse atrophies, based on the cluster classification for the cortical thickness of the brain. This research aimed to explore the degree of deteriorations in these anatomical subtypes. Genetic factors play a most important role in $\mathrm{AD}$ pathology, although biological processes which contribute to AD continue to remain undefined. Stringer et al. [34] uses the cerebrospinal fluid (CSF) proteomic approach to study the links between polygenic risk scores for $\mathrm{AD}$ and the CSF proteomic profile. The cognitive disorder profile is heterogeneous in $\mathrm{AD}$ patients. This study identified cognitive subtypes in four key $\mathrm{AD}$ cohorts with a clustering approach [13].

Biomarker detection is a challenge and a very problematic job for both medical research and data analytics [54]. Neuropathic $\mathrm{AD}$ is highly heterogeneous and recent clinical / research standards do not fully reflect the transition from the preclinical to moderate cognitive impairment to dementia. Therefore, through a brain-spinal biomarker method Toschi et al. [38] described the heterogeneous structure of $\mathrm{AD}$. Through the baseline MRI, CSF and serum biomarkers, ADNI subjects analyzed with amnestic MCI were clustered [42]. Recently few more researchers applied different models for clustering and it is tabulated in Table 3.

Table 3: Unsupervised learning models

\begin{tabular}{|c|c|c|c|c|c|}
\hline Author & Year & Model & $\begin{array}{c}\begin{array}{c}\text { Unsupervised } \\
\text { approach }\end{array} \\
\end{array}$ & Metrics & Discovery \\
\hline $\begin{array}{l}\text { Rajesh Kumar } \\
\text { et al. [53] }\end{array}$ & 2018 & $\begin{array}{c}\text { Hybrid } \\
\text { segmentation } \\
\text { technique }\end{array}$ & $\begin{array}{l}\text { K -means } \\
\text { clustering and } \\
\text { graph-cut } \\
\text { methods }\end{array}$ & Accuracy:0.85 & $\begin{array}{l}\text { Patients with AD, } \\
\text { MCI and NC were } \\
\text { identified by game } \\
\text { theory classifier. }\end{array}$ \\
\hline $\begin{array}{c}\text { Platero } \\
\text { et al. [52] }\end{array}$ & 2016 & $\begin{array}{c}\text { Fast } \\
\text { multiple-atlas } \\
\text { segmentation } \\
\text { technique }\end{array}$ & $\begin{array}{l}\text { Hippocampal } \\
\text { segmentation }\end{array}$ & Accuracy:0.91 & $\begin{array}{c}\text { This method is } \\
\text { highly applicable } \\
\text { to the } \\
\text { segmentation of } \\
\text { hippocampus and } \\
\text { is robust to } \\
\text { multi-position } \\
\text { data with } \\
\text { Harmonized } \\
\text { Hippocampal } \\
\text { Protocol } \\
\text { annotations. }\end{array}$ \\
\hline $\begin{array}{l}\text { Azimbagirad } \\
\text { et al. [48] }\end{array}$ & 2020 & $\begin{array}{l}\text { Tsallis-Entropy } \\
\text { Segmentation }\end{array}$ & $\begin{array}{c}\text { Modified } \\
\text { q-entropy (Mqe) } \\
\text { and modified } \\
\text { Markov Random } \\
\text { Field (MMRF) } \\
\text { Model }\end{array}$ & $\begin{array}{l}\text { Similarity } \\
\text { index:0.89 }\end{array}$ & $\begin{array}{l}\text { Mqe-MMRF } \\
\text { showed better } \\
\text { results than } \\
\text { FreeSurfer, SPM, } \\
\text { and FSL, } \\
\text { particularly in } \\
\text { Gray Matter. }\end{array}$ \\
\hline $\begin{array}{c}\text { Gokce } \\
\text { et al. [46] }\end{array}$ & 2020 & $\begin{array}{l}\text { Hippocampal } \\
\text { atrophy }\end{array}$ & $\begin{array}{c}\text { Semi-automatic } \\
\text { segmentation } \\
\text { software } \\
\text { ITK-SNAP }\end{array}$ & Accuracy:0.87 & $\begin{array}{l}\text { Gender wise } \\
\text { classification is } \\
\text { required in order } \\
\text { to find the severity } \\
\text { of the AD disease. }\end{array}$ \\
\hline
\end{tabular}


Ragavamsi Davuluri et al., International Journal of Emerging Trends in Engineering Research, 8(7), July 2020, 3328 - 3337

\section{CONCLUSION}

World health is badly affected by the spread and increasing Alzheimer's disease every day. The absence or delay in the care of patients can also cause death. Therefore, prediction of Alzheimer's disease is a crucial medical function. In this paper we presented different machine learning techniques for prediction of Alzheimer's disease. Some typical machine learning models are used to identify patterns of diseases of Alzheimer's and dementia. The study indicates the need to educate health workers for the accurate collection and classification methods that can be used effectively for early disease detection on medical databases. Such programs are designed to enable patients, doctors and health practitioners to make better medical decisions. Diverse models and selection strategies for the survival of Alzheimer's patients are suggested by various authors from this study.

\section{REFERENCES}

[1]. J. Ramirez, J. M. Gorriz, A. Ortiz, F. J. Martinez-Murcia, F. Segovia, D. Salas-Gonzalez, D. Castillo-Barnes, I. A. Illan, and C. G. Puntonet. Ensemble of random forests One vs. Rest classifiers for MCI and AD prediction using ANOVA cortical and subcortical feature selection and partial least squares, Journal of Neuroscience Methods, Vol. 302, pp. 47-57, May 2018.

[2]. R. C. Petersen, O. Lopez, M. J. Armstrong, T. S. D. Getchius, M. Ganguli, D. Gloss, G. S. Gronseth, D. Marson, T. Pringsheim, G. S. Day, M. Sager, J. Stevens, and A. Rae-Grant. Practice guideline update summary: Mild cognitive Impairment, Neurology, Vol. 90, pp. 126-135, Jan. 2018.

[3]. C. Hinrichs, V. Singh, L. Mukherjee, G. Xu, M. K. Chung, and S. C. Johnson. Spatially augmented LP boosting for AD classification with evaluations on the ADNI dataset, NeuroImage, Vol. 48, no. 1, pp. 138-149, Oct. 2009. https://doi.org/10.1016/j.neuroimage.2009.05.056

[4]. R. Guerrero, R. Wolz, A. W. Rao, and D. Rueckert. Manifold population modeling as a neuro-imaging biomarker: Application to ADNI and ADNI-GO, NeuroImage, Vol. 94, pp. 275-286, Jul. 2014.

[5]. J. Hwang, C. M. Kima, S. Jeon, J. M. Lee, Y. J. Hong, J. H. Roh, J. Lee, J. Koh, and D. L. Na. Prediction of Alzheimer's disease pathophysiology based on cortical thickness patterns, Alzheimer's \& Dementia, Vol. 2, pp. 58-67, Dec. 2015.

https://doi.org/10.1016/j.dadm.2015.11.008

[6]. R. Khoury, and E. Ghossoub. Diagnostic biomarkers of Alzheimer's disease: A state-of-the-art review, Biomarkers in Neuropsychiatry, Vol. 1, Dec. 2019.

[7]. M. S. Fiandacaa, M. E. Mapstone, A. K. Cheema, and H. J. Federoff. The critical need for defining preclinical biomarkers in Alzheimer's disease, Alzheimer's \& Dementia, Vol. 10, pp. S196-S212, Jun. 2014.

[8]. S. D. Stites, R. Milne, and J. Karlawish. Advances in Alzheimer's imaging are changing the experience of
Alzheimer's disease, Alzheimer's \& Dementia, Vol. 10, pp. 285-300, Mar. 2018.

[9]. J. Tohka, E. Moradi, and H. Huttunen. Comparison of Feature Selection Techniques in Machine Learning for Anatomical Brain MRI in Dementia, Neuroinformatics, Vol. 14, pp. 279-296, Jan. 2016. https://doi.org/10.1007/s12021-015-9292-3

[10]. J. M. Rondina, L. K. Ferreira, F. L. D. S. Duran, R. Kubo, C. R. Ono, C. C. Leite, J. Smid, R. Nitrini, C. A. Buchpiguel, and G. F. Busatto. Selecting the most relevant brain regions to discriminate Alzheimer's disease patients from healthy controls using multiple kernel learning: A comparison across functional and structural imaging modalities and atlases, NeuroImage: Clinical, Vol. 17, pp. 628-641, Nov. 2017.

[11]. J. Young, M. Modat, M. J. Cardoso, A. Mendelson, D. Cash, and S. Ourselin. Accurate multimodal probabilistic prediction of conversion to Alzheimer's disease in patients with mild cognitive impairment, NeuroImage: Clinical, Vol. 2, pp. 735-745, Dec. 2013.

[12]. J. Escudero, and J. P. Zajicek. Machine Learning Classification of MRI Features of Alzheimer's Disease and Mild Cognitive Impairment Subjects to Reduce the Sample Size in Clinical Trials, in Proc. 33rd Annual International Conference of the IEEE, Boston, Massachusetts, USA, 2011.

[13]. N. M. E. Scheltens, B. M. Tijms, T. Koene, F. Barkhof, C. E. Teunissen, S. Wolfsgruber, M. Wagner, J. Kornhuber, O. Peters, B. I. Cohn-Sheehy, G. D. Rabinovici, B. L. Miller, J. H. Kramer, P. Scheltens, and W. M. V.Flier. Cognitive subtypes of probable Alzheimer's disease robustly identified in four cohorts, Alzheimer's \& Dementia, Vol. 13, pp. 1226-1236, Nov. 2017.

https://doi.org/10.1016/j.jalz.2017.03.002

[14]. S. H. Immanuel, and S. G. Jacob. Feature Selection Techniques for Alzheimer's Disease: A Review, International Journal of Engineering Technology Science and Research, Vol. 4, no. 7, pp. 494-499, Jul. 2017.

[15]. E. E. Tripoliti , D. I. Fotiadis, M. Argyropoulou, and G. Manis. A six stage approach for the diagnosis of the Alzheimer's disease based on fMRI data, Journal of Biomedical Informatics, Vol. 43, no. 2, pp. 307-320, Apr. 2010.

[16]. R. B. Mofrad, N. S. M. Schoonenboom, B. M. Tijms, P. Scheltens, P. J. Visser, W. M. V. Flier, and C. E. Teunissen. Decision tree supports the interpretation of CSF biomarkers in Alzheimer's disease, Alzheimer's \& Dementia, Vol. 11, no. 1, pp. 1-9, Dec. 2019.

[17]. C. Plant, S. J. Teipel, A. Oswald, C. Böhm, T. Meindl, J. Mourao-Miranda, A. W. Bokde, H. Hampel, and M. Ewers. Automated detection of brain atrophy patterns based on MRI for the prediction of Alzheimer's disease, NeuroImage, Vol. 50, no. 1, pp. 162-174, Mar. 2010.

[18]. S. Matoug, A. Abdel-Dayem, K. Passi, W. Gross, and M. Alqarni. Predicting Alzheimer's disease by classifying 3D-Brain MRI images using SVM and other 
Ragavamsi Davuluri et al., International Journal of Emerging Trends in Engineering Research, 8(7), July 2020, 3328 - 3337

well-defined classifiers, Journal of Physics: conference series, Vol. 34, 2012.

[19]. D. Impedovo, and G. Pirlo. Dynamic handwriting analysis for the assessment of neurodegenerative diseases: a pattern recognition perspective, IEEE Reviews in Biomedical Engineering, Vol. 12, pp. 209-220, May 2018.

https://doi.org/10.1109/RBME.2018.2840679

[20]. F. Kruggel, F. Masaki, and A. Solodkin. Analysis of longitudinal diffusion-weighted images in healthy and pathological aging: An ADNI study, Journal of Neuroscience Methods, Vol. 278, pp. 101-115, Feb. 2017.

[21]. P. M. Rodrigues, D. Freitas, and J. P. Teixeira. Alzheimer electroencephalogram temporal events detection by K-means, in Proc. International Conf. on Health and Social Care Information Systems and Technologies, Portugal, 2012, pp. 859-864.

[22]. Z. Sun, Y. Qiao, B. P. F. Lelieveldt, and M. Staring. Integrating spatial-anatomical regularization and structure sparsity into SVM: Improving interpretation of Alzheimer's disease classification, NeuroImage, Vol. 178, pp. 445-460, Sep. 2018.

[23]. D. Schmitter, A. Roche, B. Maréchal, D. Ribes, A. Abdulkadir, M. Bach-Cuadra, A. Daducci, C. Granziera, S. Klöppel, P. Maeder, R. Meuli, and G. Krueger. An evaluation of volume-based morphometry for prediction of mild cognitive impairment and Alzheimer's disease, NeuroImage: Clinical, Vol. 7, pp. 7-17, Nov. 2014. https://doi.org/10.1016/j.nicl.2014.11.001

[24]. W. Shao, Y. Peng, C. Zu, M. Wang, and D. Zhang. Hypergraph based multi-task feature selection for multimodal classification of Alzheimer's disease, Computerized Medical Imaging and Graphics, Vol. 80, 2020.

[25]. K. Poulakis, J. B. Pereira, P. Mecocci, B. Vellas, M. Tsolaki, I. Kloszewska, H. Soininen , S. Lovestone, A. Simmons, L. Wahlund, and E. Westman. Heterogeneous patterns of brain atrophy in Alzheimer's disease, Neurobiology of Aging, Vol. 65, pp. 98-108, May 2018.

[26]. T. Altaf, S. M. Anwar, N. Gul, M. N. Majeed, and M. Majid. Multi-class Alzheimer's disease classification using image and clinical features, Biomedical Signal Processing and Control, Vol. 43, pp. 64-74, May 2018.

[27]. J. Liu, J. Wang, B. Hu, F. Wu, and Y. Pan. Alzheimer's disease classification based on individual hierarchical networks constructed with 3-D texture features, IEEE Transactions on NanoBioscience, Vol. 16, no. 6, pp. 428-437, Sep. 2017.

https://doi.org/10.1109/TNB.2017.2707139

[28]. H. K. Na, D. R. Kang, S. Kim, S. W. Seo, K. M. Heilman, Y. Noh, and D. L. Na. Malignant progression in parietal-dominant atrophy subtype of Alzheimer's disease occurs independent of onset age, Neurobiology of Aging, Vol. 47, pp. 149-156, Aug. 2016.

[29]. K.Tejeswinee, S. G. Jacob, and Athilakshmi. R. Feature Selection Techniques for Prediction of Neuro-Degenerative Disorders: A Case-Study with
Alzheimer's And Parkinson's Disease, in Proc. of 7th International Conf. on Advances in Computing \& Communications, Cochin, India, 2017, pp. 188-194.

[30]. D. Jain, and V. Singh. Feature selection and classification systems for chronic disease prediction: A review, Egyptian Informatics Journal, Vol. 19, pp. 179-189, Apr. 2018.

[31]. M. Dadar, J. Maranzano, S. Ducharme, O. T. Carmichael, C. Decarli, and D. L. Collins. Validation of T1w-based segmentations of white matter hyperintensity volumes in large-scale datasets of aging, Hum Brain Mapping, Vol. 39, pp. 1093-1107, Nov. 2017.

https://doi.org/10.1002/hbm.23894

[32]. L. Sørensen, and M. Nielsen. Ensemble support vector machine classification of dementia using structural MRI and mini-mental state examination, Journal of Neuroscience Methods, Vol. 302, pp. 66-74, Jan. 2018.

[33]. J. Ye, M. Farnum, E. Yang, R. Verbeeck, V. Lobanov, N. Raghavan, G. Novak, A. DiBernardo, and V. A. Narayan. Sparse learning and stability selection for predicting MCI to AD conversion using baseline ADNI data, $B M C$ Neurology, Vol. 12, no. 46, Jun. 2012.

[34]. L. M. Reus, S. Stringer, D. Posthuma, C. E. Teunissen, P. Scheltens, Y. A. L. Pijnenburg, P. J. Visser, and B. M. Tijms. Degree of Genetic Liability for Alzheimer's Disease Associated with Specific Proteomic Profiles in Cerebrospinal Fluid, Neurobiology of Aging, Vol. 93, pp. 144.e1-144.e15, Mar. 2020.

[35]. F. Zhang, S. Tian, S. Chen, Y. Ma, X. Li, and X. Guo. Diagnosis of Alzheimer's Disease Based on Structural MRI Images Using a Regularized Extreme Learning Machine and PCA Features, Neuroscience, Vol. 414, pp. 273-279, Jun. 2017.

[36]. S. R. B. D. S. Filhoa, J. H. O. Barbosab, C. Rondinonia, A. C. D. Santosa, C. E. G. Salmonb, N. K. D. C. Limaa, E. Ferriollia, and J. C. Morigutia. Neuro-degeneration profile of Alzheimer's patients: A brain morphometry study, NeuroImage: Clinical, Vol. 15, pp. 15-24, Apr. 2017.

[37]. K. Ritter, J. Schumacher, M. Weygandt, R. Buchert, C. Allefeld, and J. Haynes. Multimodal prediction of conversion to Alzheimer's disease based on incomplete biomarkers, Alzheimer's \& Dementia, Vol. 1, pp. 206-215, Apr. 2015.

[38]. N. Toschi, S. Lista, F. Baldacci, E. Cavedo, H. Zetterberg, K. Blennow, I. Kilimann, S. J. Teipel, A. M. D. Santos, S. Epelbaum, F. Lamari, R. Genthon, M. Habert, B. Dubois, R. Floris, F. Garaci, A. Vergallo, and H. Hampel. Biomarker-guided clustering of Alzheimer's disease clinical syndromes, Neurobiology of Aging, Vol. 83, pp. 42-53, Nov. 2019.

[39]. P. Hoffman, S. A. Sajjadi, K. Patterson, and P. J. Nestor. Data-driven classification of patients with primary progressive aphasia, Brain and Language, Vol. 174, pp. 86-93, Nov. 2017.

https://doi.org/10.1016/j.bandl.2017.08.001 
Ragavamsi Davuluri et al., International Journal of Emerging Trends in Engineering Research, 8(7), July 2020, 3328 - 3337

[40]. C. B. Malpas. Structural neuroimaging correlates of cognitive status in older adults: A person-oriented approach, Journal of Clinical Neuroscience, Vol. 30, pp. 77-82, Apr. 2016.

[41]. E. Westman, A. Simmons, J. Muehlboeck, P. Mecocci, B. Vellas, M. Tsolaki, I. Kłoszewska, H. Soininen, M. W. Weiner, S. Lovestone, C. Spenger, and L. Wahlund. AddNeuroMed and ADNI: Similar patterns of Alzheimer's atrophy and automated MRI classification accuracy in Europe and North America, NeuroImage, Vol. 58, pp. 818-828, Oct. 2011.

[42]. J. Nettiksimmons, C. DeCarli, S. Landau, and L. Beckett. Biological heterogeneity in ADNI amnestic mild cognitive impairment, Alzheimer's \& Dementia, Vol. 10, no. 5, pp. 511-521, Jan. 2014.

https://doi.org/10.1016/j.jalz.2013.09.003

[43]. K. R. Kruthika, Rajeswari, and H. D. Maheshappa. Multistage classifier-based approach for Alzheimer's disease prediction and retrieval, Informatics in Medicine Unlocked, Vol. 14, pp. 34-42, Dec. 2018.

[44]. L. Wang, Y. Liu, X. Zeng, H. Cheng, Z. Wang, and Q. Wang. Region-of-Interest Based Sparse Feature Learning Method for Alzheimer's Disease Identification, Computer Methods and Programs in Biomedicine, Vol. 187, Dec. 2019.

[45]. P. A. Cicalesea, R. Lia, M. B. Ahmadia, C. Wangb, J. T. Francisa, S. Selvarajc, P. E. Schulzc, and Y. Zhanga. An EEG-fNIRS Hybridization Technique in the Four-Class Classification of Alzheimer's Disease, Journal of Neuroscience Methods, Vol. 336, Jan. 2020.

[46]. G. Uysala, and M. Ozturk. Hippocampal atrophy based Alzheimer's disease diagnosis via machine learning methods, Journal of Neuroscience Methods, Vol. 337, May 2020.

[47]. J. P. Kima, J. Kimb, Y. H. Parka, S. B. Parka, J. S. Leed, S. Yooe, E. Kimf, H. J. Kima, D. L. Naa, J. A. Browng, S. N. Lockharth, S. W. Seoa, and J. Seongb. Machine learning based hierarchical classification of frontotemporal dementia and Alzheimer's disease, Neurolmage: Clinical, Vol. 23, Apr. 2019.

[48]. M. Azimbagirada, F. H. Simozo, A. C. S. S. Filhoa, and L. O. M. Junior. Tsallis-Entropy Segmentation through MRF and Alzheimer anatomic reference for Brain Magnetic Resonance Parcellation, Magnetic Resonance Imaging, Vol. 65, pp. 136-145, Jan. 2020.

[49]. X. Hao, Y. Bao, Y. Guo, M. Yu, D. Zhang, S. L. Risacherc, A. J. Saykinc, X. Yao, and L. Shen. Multi-modal Neuroimaging Feature Selection with Consistent Metric Constraint for Diagnosis of Alzheimer's Disease, Medical Image Analysis, Vol. 60, Jan. 2020.

https://doi.org/10.1016/j.media.2019.101625

[50]. J. Li, L. Wu, G. Wen, and Z. Li. Exclusive feature selection and multi-view learning for Alzheimer's Disease, J. Vis. Commun. Image R, Vol. 64, Aug. 2019.

[51]. S. Mirzaeia, M. ElYacoubia, S. Garcia-Salicettia, J. Boudya, C. Kahindoa, V. Cristancho-Lacroixb, H. Kerhervéb, and A. S. Rigaudc. Two-Stage Feature
Selection of Voice Parameters for Early Alzheimer's Disease Prediction, IRBM, Vol. 39, no. 6, pp. 430-435, Oct. 2018.

[52]. C. Platero, and M. C. Tobar. A fast approach for hippocampal segmentation from T1-MRI for predicting progression in Alzheimer's disease from elderly controls, Journal of Neuroscience Methods, Vol. 270, pp. 61-75, Jun. 2016.

[53]. P. Rajesh Kumar, T. Arunprasath, M. P. Rajasekaran, and G. Vishnuvarthanan. Computer-aided automated discrimination of Alzheimer's disease and its clinical progression in magnetic resonance images using hybrid clustering and game theory-based classification strategies, Computers and Electrical Engineering, Vol. 72, pp. 283-295, Sep. 2018.

[54]. D. Gamberger, B. Zenko, A. Mitelpunkt, and N. Lavra. Homogeneous clusters of Alzheimer's disease patient population, in Proc. 3rd International Work-Conf. on Bioinformatics and Biomedical Engineering, Grenada, Spain, 2015, pp. 15-17.

https://doi.org/10.1186/s12938-016-0183-0

[55]. L. R. Trambaiolli, N. Spolaôr, A. C. Lorena, R. Anghinah, and J. R. Sato. Feature selection before EEG classification supports the diagnosis of Alzheimer's disease, Clinical Neurophysiology, Vol. 128, no. 10, pp. 2058-2067, Jun. 2017.

[56]. K. Vaithinathana, and L. Parthibanb. A Novel Texture Extraction Technique with T1 Weighted MRI for the Classification of Alzheimer's Disease, Journal of Neuroscience Methods, Vol. 318, pp. 84-99, Apr. 2019.

[57]. D. A. Anggoro, and N. Devi Kurina. Comparison of Accuracy Level of Support Vector Machine (SVM) and K-Nearest Neighbors (KNN) Algorithms in Predicting Heart Disease, International Journal of Emerging Trends in Engineering Research, Vol. 8, no. 5, May 2020. https://doi.org/10.30534/ijeter/2020/32852020

[58]. L. P. Maguluri, and R. Ragupathy. An Efficient Stock Market Trend Prediction Using the Real-Time Stock Technical Data and Stock Social Media Data, International Journal of Intelligent Engineering and Systems, Vol. 13, no. 4, May 2020.

[59]. B. Anilkumar, and P. Rajesh Kumar. Tumor Classification using Block wise fine tuning and Transfer learning of Deep Neural Network and KNN Classifier on MR Brain Images, International Journal of Emerging Trends in Engineering Research, Vol 8, no. 2, Feb. 2020. https://doi.org/10.30534/ijeter/2020/48822020 